\begin{tabular}{|c|c|c|}
\hline & Int.J.Curr.Microbiol.App.Sci (2018) 7(3): xx-xx & \multirow{2}{*}{ 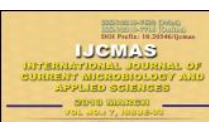 } \\
\hline & \multirow{3}{*}{$\begin{array}{l}\text { International Journal of Current Microbiology and Applied Sciences } \\
\text { ISSN: 2319-7706 Volume } 7 \text { Number } 03 \text { (2018) } \\
\text { Journal homepage: http://www.ijcmas.com }\end{array}$} & \\
\hline & & \\
\hline $\begin{array}{l}\text { EXCELLENT } \\
\text { PUBLISHERS }\end{array}$ & & \\
\hline
\end{tabular}

Original Research Article https://doi.org/10.20546/ijcmas.2018.703.417

\title{
Gender Empowerment about Livelihood Programmes of TSP in Southern Rajasthan, India
}

\author{
Yogita Ranawat ${ }^{1}$, S.S. Sisodia ${ }^{1}$, Vikas Kumar ${ }^{2 *}$ and H.K. Jain ${ }^{3}$ \\ ${ }^{1}$ Department of Extension Education, RCA (MPUA\&T), Udaipur, Rajasthan-313001, India \\ ${ }^{2}$ Department of Extension Education, SKNAU, Jobner Rajasthan-303328, India \\ ${ }^{3}$ Department of Statistics RCA (MPUA\&T), Udaipur, Rajasthan-313001, India \\ *Corresponding author
}

\section{A B S T R A C T}

Tribal people are working hard in farming but due to unfertile and un-even land, lack of irrigation facilities, traditional methods of agriculture, illiteracy and poverty they are getting low income from farming as compared to other groups of people making it difficult

Keywords

Gender,

Empowerment,

Livelihood and TSP

Article Info

Accepted:

28 February 2018

Available Online:

10 March 2018 for them to maintain their family need and living standard forcing them other economical occupation like, agriculture labour, construction work and seasonal works etc. The present study was conducted in two districts, namely, Banswara and Dungarpur of southern Rajasthan, having highest per cent of tribals in the state. Banswara and Dungarpur register the highest concentration of 72.3 and 65.14 per cent of tribals respectively. Total respondents included in the study were 150 , out of which 75 male and 75 female TSP beneficiaries were them. Proportionate random sampling technique was employed for the selection of respondents. From each village equal number of male and female respondents was sought for the present study. In case of Social empowerment respondents adequately empowered their participation in village administration. But male involvement was poor in addressing social issues and problems, whereas, female were unable to involve in decision making. In case of economic empowerment, male respondents after implementation of TSP programme got improvement in family income but they were unable in repayment of debt in time. Whereas, female were capable to stabilized their income but unable to develop savings habit.

\section{Introduction}

Socio - economic upliftment programmes of tribal cannot be ignored while planning agriculture and other development programmes of the country. Since the tribal population of the country constitute 7.83 per cent of the total population. Tribals are amongst the weakest sections of the society. Tribal people are working hard in farming but due to unfertile and un-even land, lack of irrigation facilities, traditional methods of agriculture, illiteracy and poverty they are getting low income from farming as compared to other groups of people making it difficult for them to maintain their family need and living standard forcing them other economical occupation like, agriculture labour, construction work and seasonal works etc. 
Tribal Sub-Plan (TSP) is a strategic policy initiative to secure overall development of STs' was first introduced in the Fifth Five Year Plan. The focus of TSP is on "securing budgetary allocations for tribal development at least proportionate to their population in order to bring them at par with other sections of society and to protect them from exploitation." With the fast developing world, tribal's required specific attention not only with monetary allocation but along with special interventions for their rapid socio-economic development through integrated approach of all departments in a united manner. The Tribal Sub-Plan envisage reducing gap between the tribals and non-tribals in health, education, communication and other areas of basic amenities of life by providing legal and administrative support. The Sub-Plan also implements income generating schemes to boost income of the tribals on a sustainable basis by taking into account their aptitude and skill.

\section{Materials and Methods}

The present study was conducted in two districts, namely, Banswara and Dungarpur of southern Rajasthan, having highest per cent of tribals in the state. Banswara and Dungarpur register the highest concentration of 72.3 and 65.14 per cent of tribals respectively. Two tehsils, namely, Banswara and Dungarpur were selected for this study. The criterion fixed for selection of tehsil from each district was that which had $1^{\text {st }}$ and foremost place as far as its total population is concerned. The study was undertaken in 10 villages of selected tehsils. First five villages of both the districts based on highest population were drawn up and included for the investigation.

Total respondents included in the study were 150, out of which 75 male and 75 female TSP beneficiaries were them. Proportionate random sampling technique was employed for the selection of respondents. From each village equal number of male and female respondents was sought for the present study.

\section{Distribution of respondents according to level of gender empowerment}

The respondents were divided into three groups on the basis of their level of gender empowerment with the help of obtained mean score and standard deviation. The data related to the gender empowerment of both the category of respondents i.e., male and female indicate that respondents gender empowerment for livelihood programmes had a wide dispersion. In order to place the respondents into their appropriate categories, gender empowerment score were categorized and reported in Table 1.

The data presented in Table 1 revealed that majority of male respondents empowered medium followed by low and high empowerment with 25.33 and 21.33 per cent, respectively. Table indicates that 48.00 per cent female respondents were medium level empowered followed by low and high empowerment with 34.67 and 17.33 per cent respondents, respectively.

Data of Table 1 further shows that 50.67 per cent male and female fall in the medium level empowerment group this was followed by low and high empowerment group with 30.00 and 19.33 per cent respectively.

It can be further concluded that 75.00 per cent respondents from male respondents were to be observed either from medium or high empowerment group. Whereas, 70 per cent female respondents empowerment was medium to lower level in the study area. The psychological, social, economic and political empowerment of men respondents was found to be significantly different than female respondents. 
Extent of gender empowerment in ongoing programmes in TSP area

The empowerment of male and female respondents with regards to livelihood programmes were measured in terms of Mean Percent Score (MPS). Four type of gender empowerment i.e. Psychological, Social, Economic and Political Empowerment were included to assess the gender empowerment regarding livelihood programmes in TSP area.

\section{Psychological empowerment}

The Table 1 shows that male respondents have high risk bearing ability and self-confidence with 85.97 and 76.26 MPS, respectively. Selfrespect and aspiration of male respondents also improved with 66.12 and 52.52 MPS, respectively. But they were unable to improved self-esteem.

Data of Table 1 also indicates that female respondents have highly improved self-respect and self-confidence with 77.70 and 71.28 MPS, respectively. Respondent's also improved risk bearing ability with 61.46 MPS. But women respondents unable to improved aspiration and self-esteem with 45.31 and 38.92 MPS, respectively.

If we look at Table 1 data shows that both male and female respondents had better empowered (above 70\%) in aspects like selfconfidence, risk bearing ability and selfrespect with 73.77, 73.71 and 71.91 MPS, respectively. But still they were lacking in aspiration and self-esteem.

\section{Social Empowerment}

Data of Table 2 shows that male respondents better empowered (above 70\%) regarding participation in village administration and socio-economic development awareness with 77.09 and 75.08 MPS, respectively. They were capable to decision making but their involvement was poor in addressing social issues and problems.

The Table 2 data shows that female respondents were empowered to participation in village administration with 65.04 MPS. Respondent's also empowered in aspects like awareness of socio - economic development activities with 60.63 MPS. They were unable to actively involved in addressing social issues and problems and also in decision making.

Table 2 further shows that male and female respondents adequately empowered regarding participation in village administration with 71.07 MPS. Respondent's acquired awareness of socio - economic development activities with 67.85 MPS.

They were incapable in decision making and could not actively involve in addressing social issues and problems.

\section{Economic empowerment}

The Table 3 further shows that male respondents after implementation of TSP programme got improvement in family income and stabilized income with 75.94 and 75.35 MPS, respectively. Respondent's standard of living improved and increase in annual savings with 63.46 and 52.23 MPS, respectively. But they were unable in develop savings habit and repayment of debt in time.

Data of Table 3 also indicates that female beneficiaries after implementation of TSP were capable to stabilized income and got improvement in family income with 70.96 and 67.13 MPS, respectively.

Respondent's annual savings improved with 57.57 MPS. But they were unable in repayment of debt in time and developed of savings habit. 
Table.1 Distribution of respondents according to their empowerment

\begin{tabular}{|c|l|c|c|c|c|c|c|}
\hline S. & \multicolumn{1}{|c|}{$\begin{array}{c}\text { Level of Gender } \\
\text { No. }\end{array}$} & \multicolumn{1}{|c|}{ Male $(\mathbf{n}=\mathbf{7 5})$} & \multicolumn{2}{|c|}{ Female $(\mathbf{n}=\mathbf{7 5})$} & \multicolumn{2}{|c|}{ Total $(\mathbf{n}=\mathbf{1 5 0})$} \\
\hline 1. & $\begin{array}{l}\text { Low empowerment } \\
\text { (<36 score) }\end{array}$ & $\mathbf{f}$ & $\mathbf{\%}$ & $\mathbf{f}$ & $\mathbf{\%}$ & $\mathbf{f}$ & $\mathbf{\%}$ \\
\hline 2. & $\begin{array}{l}\text { Medium empowerment } \\
\text { (36-41 score) }\end{array}$ & 40 & 53.34 & 36 & 48.00 & 76 & 50.67 \\
\hline 3. & $\begin{array}{l}\text { High empowerment } \\
\text { (> 41score) }\end{array}$ & 16 & 21.33 & 13 & 17.33 & 29 & 19.33 \\
\hline
\end{tabular}

$\mathrm{f}=$ frequency, $\%=$ percentage, $\mathrm{n}=$ number of respondents

Table.2 Psychological empowerment of beneficiaries in TSP area

\begin{tabular}{|c|l|c|c|c|c|c|c|}
\hline \multicolumn{1}{|c|}{ Sspects } & \multicolumn{2}{|c|}{ Male $(\mathbf{n}=\mathbf{7 5})$} & \multicolumn{3}{c|}{ Female $(\mathbf{n}=\mathbf{7 5})$} & Total $(\mathbf{n}=\mathbf{1 5 0})$ \\
\hline No. & & MPS & Rank & MPS & Rank & MPS & Rank \\
\hline 1. & Aspiration & 52.52 & 4 & 45.31 & 4 & 48.91 & 4 \\
\hline 2. & Self esteem & 43.61 & 5 & 38.92 & 5 & 41.27 & 5 \\
\hline 3. & Self confidence & 76.26 & 2 & 71.28 & 2 & 73.77 & 1 \\
\hline 4. & Risk bearing ability & 85.97 & 1 & 61.46 & 3 & 73.71 & 2 \\
\hline 5. & Self respect & 66.12 & 3 & 77.70 & 1 & 71.91 & 3 \\
\hline
\end{tabular}

MPS $=$ mean percent score, $\mathrm{n}=$ number of respondents

Table.3 Social empowerment about livelihood Programmes in TSP area

\begin{tabular}{|c|c|c|c|c|c|c|c|}
\hline \multirow[t]{2}{*}{ S. No. } & \multirow[t]{2}{*}{ Statement } & \multicolumn{2}{|c|}{ Male $(n=75)$} & \multicolumn{2}{|c|}{ Female $(\mathrm{n}=75)$} & \multicolumn{2}{|c|}{ Total $(n=150)$} \\
\hline & & MPS & Rank & MPS & Rank & MPS & Rank \\
\hline 1 & $\begin{array}{l}\text { Awareness of socio - economic } \\
\text { development }\end{array}$ & 75.08 & 2 & 60.63 & 2 & 67.85 & 2 \\
\hline 2 & Participation in village administration & 77.09 & 1 & 65.04 & 1 & 71.07 & 1 \\
\hline 3 & $\begin{array}{l}\text { Actively involved in addressing social } \\
\text { issues and problems }\end{array}$ & 52.88 & 4 & 53.96 & 3 & 53.42 & 4 \\
\hline 4 & Capable of decision making & 54.54 & 3 & 53.82 & 4 & 54.18 & 3 \\
\hline
\end{tabular}

MPS $=$ mean percent score, $\mathrm{n}=$ number of respondents

Table.4 Economic empowerment of beneficiaries in TSP area

\begin{tabular}{|l|l|c|c|c|c|c|c|} 
S. No. & \multicolumn{1}{|c|}{ Statement } & \multicolumn{2}{|c|}{ Male $(\mathbf{n}=\mathbf{7 5})$} & \multicolumn{3}{c|}{ Female $(\mathbf{n}=\mathbf{7 5})$} & \multicolumn{2}{c|}{ Total $(\mathbf{n}=\mathbf{1 5 0})$} \\
\hline $\mathbf{1}$ & Stabilized income & MPS & Rank & MPS & Rank & MPS & Rank \\
\hline $\mathbf{2}$ & Improvement in family income & 75.35 & 2 & 70.96 & 1 & 73.15 & 1 \\
\hline $\mathbf{3}$ & Development of savings habit & 75.94 & 1 & 67.13 & 2 & 71.53 & 2 \\
\hline $\mathbf{4}$ & Increase in annual savings & 43.25 & 5 & 36.72 & 6 & 39.98 & 5 \\
\hline $\mathbf{5}$ & Improvement in standard of living & 52.23 & 4 & 57.57 & 3 & 54.90 & 4 \\
\hline $\mathbf{6}$ & Repayment of debt in time & 63.46 & 3 & 55.70 & 4 & 59.58 & 3 \\
\hline
\end{tabular}

MPS $=$ mean percent score, $\mathrm{n}=$ number of respondents 
Table.5 Political empowerment of TSP beneficiaries

\begin{tabular}{|c|c|c|c|c|c|c|c|}
\hline \multirow[t]{2}{*}{$\begin{array}{c}\text { S. } \\
\text { No. }\end{array}$} & \multirow[t]{2}{*}{ Statement } & \multicolumn{2}{|c|}{ Male $(n=75)$} & \multicolumn{2}{|c|}{$\begin{array}{c}\text { Female }(n= \\
75)\end{array}$} & \multicolumn{2}{|c|}{$\begin{array}{c}\text { Total }(\mathrm{n}= \\
150)\end{array}$} \\
\hline & & MPS & Rank & MPS & Rank & MPS & Rank \\
\hline 1 & $\begin{array}{l}\text { Participation became able to } \\
\text { participate in political process } \\
\text { like contesting election }\end{array}$ & 70.45 & 1 & 57.03 & 1 & 63.74 & 1 \\
\hline 2 & Member of local political party & 47.76 & 2 & 41.37 & 2 & 44.57 & 2 \\
\hline 3 & Taking leadership position & 43.47 & 3 & 40.65 & 3 & 42.06 & 3 \\
\hline
\end{tabular}

MPS= mean percent score, $n=$ number of respondents

Table.6 Comparison of gender empowerment in ongoing programmes in TSP area

\begin{tabular}{|l|l|c|c|c|c|c|}
\multirow{2}{*}{ S. No. } & Category of Empowerment & \multicolumn{2}{|c|}{ Male } & \multicolumn{2}{c|}{ Female } & ' $Z$ ' Value \\
\cline { 3 - 8 } & & Mean & SD & Mean & SD & \\
\hline $\mathbf{1}$ & Psychological empowerment & 8.23 & 1.13 & 7.81 & 1.16 & $2.20^{*}$ \\
\hline $\mathbf{2}$ & Social empowerment & 8.96 & 0.74 & 8.51 & 1.21 & $2.76^{* *}$ \\
\hline $\mathbf{3}$ & Economic empowerment & 13.31 & 1.72 & 12.43 & 2.31 & $2.64^{* *}$ \\
\hline $\mathbf{4}$ & Political empowerment & 9.60 & 1.67 & 8.72 & 1.80 & $3.10^{* *}$ \\
\hline
\end{tabular}

$\mathrm{NS}=$ Non Significant,$* *=$ Significant at $1 \%$ level of significance, $*=$ Significant at $5 \%$ level of significance

Data of Table 3 also indicates that male and female TSP beneficiaries could able to stabilized income and observing improvement in family income with 73.15 and 71.53 MPS, respectively. Respondent's standard of living improved and annual savings increased with 59.58 and 54.90 MPS, respectively. They were unable in repayment of debt in time and development of savings habit.

\section{Political empowerment}

The table 4 shows that male beneficiaries of TSP area became able to participate in political process like contesting election with 70.45 MPS and they also became member of local political party with 47.76 MPS. But only few of them could get leadership position.

Data of table 4 also indicates that female beneficiaries of TSP programme became able to participate in political process like contesting election with 57.03 MPS followed by member of local political party and taking leadership position with 41.37 and 40.65 MPS, respectively. If we look at Table 4 irrespective of male and female respondents data shows that TSP beneficiaries after implementation of programme became able to participate in political process like contesting election with 63.74 MPS and they also became member of local political party and able in taking leadership position with $2^{\text {nd }}$ and $3^{\text {rd }}$ rank, respectively (Table 5).

\section{Comparison of gender empowerment in ongoing programmes in TSP area}

In addition to study of gender empowerment of male and female respondents of TSP with regard to livelihood security, further efforts were made to study the difference between male and female respondents gender empowerment in TSP area. To find out the variation in the participation of the respondent ' $Z$ ' test was applied. The results are presented in Table 6. 
$\mathrm{H}_{\mathrm{o}}$ : There is no difference in the gender empowerment of male and female respondents about ongoing livelihood programs.

$\mathrm{H}_{1}$ : There is difference in the gender empowerment of male and female respondents about ongoing livelihood programs.

The data related to level of gender empowerment of both male and female respondents incorporated in Table 6 shows that in psychological empowerment calculated ' $Z$ ' value was higher than the tabulated value at 5 per cent level of significance and social, economic and political empowerment calculated ' $Z$ ' value was higher than the tabulated value at 1 per cent level of significance of gender empowerment in ongoing programmes in TSP area.

This call for rejection of null hypothesis and acceptance of alternative hypothesis, leading to conclusion that there is significant difference in gender empowerment with regard to ongoing programmes in male and female respondents. This difference in the gender empowerment of tribal might be due to the reason that male respondents had highly educated, actively participation in social issues \& problems, highly awareness and capable of decision making. In other words, there is no similarity between the extent of gender empowerment of male and female respondents in TSP area.

The present findings of the study are supported by the findings of Barua (2012) who reported that the difference is significant at both 0.05 and 0.01 level of confidence. Hence, highly significant difference was found in male and female empowerment. Women empowerment was found significantly lower than men empowerment.
To enhance women empowerment re orientation of policy under TSP is needed.

In case of psychological empowerment, male respondents highly improved risk bearing ability and self-confidence with 85.97 and 76.26 MPS, respectively. Whereas, female respondents highly improved self-respect and self-confidence with 77.70 and 71.28 MPS, respectively. But they were unable to improved self-esteem.

In case of social empowerment, male and female respondents adequately empowered their participation in village administration and both assigned $1^{\text {st }}$ rank. But, male involvement was poor in addressing social issues and problems whereas, female were unable to involve in decision making.

In case of economic empowerment, male respondents after implementation of TSP programme got improvement in family income with 75.94 MPS but they were unable in repayment of debt in time. Whereas, female were capable to stabilized income but unable to develop savings habit.

Similarly in case of political empowerment, irrespective of male and female respondents data shows that TSP beneficiaries after implementation of programme became able to participate in political process like contesting election with 63.74 MPS and also became member of local political party and able in taking leadership position with $2^{\text {nd }}$ and $3^{\text {rd }}$ rank, respectively.

\section{References}

Barua, S. 2012. Impact Assessment of Tribal Sub Plan on Livelihood Security in West Bengal. M.Sc. (Agri.) Thesis, Indian Agricultural Research Institute, New Delhi

Bheemappa, 2006. A study on knowledge level of Gram panchayat members 
about Sampoorna Grameena Rozgar Yojana in Raichur district of Karnataka. M.Sc. (Agri.) Thesis, University of Agricultural Sciences, Dharwad.

Jat, H. L., Neeta, Badhala, B. S. and Meena, D. K. 2012. Awareness of respondents about Swarnjayanti Gram Swarozgar Yojana. Abstract in International conference on Extension Education in the perspectives of Advances in Natural Resource Management in Agriculture (NaRMA-IV). SKRAU,
Bikaner.

Ravjibhai, M.K. 2006. Role of tribal farmwomen in Agricultural development in integrated tribal development project areas of Dahod District of Gujarat State. Ph. D. Thesis, Anand Agricultural University, Anand.

Srivastav, R. and Rankawat, K. 2012. Impact of Nutrition Education on rural women of Jodhpur Region. Rajasthan Journal of Extension Education, 20: 22-26.

\section{How to cite this article:}

Yogita Ranawat, S.S. Sisodia, Vikas Kumar and Jain, H.K. 2018. Gender Empowerment about Livelihood Programmes of TSP in Southern Rajasthan, India. Int.J.Curr.Microbiol.App.Sci. 7(03): 3616-3622. doi: https://doi.org/10.20546/ijcmas.2018.703.417 